\title{
Chemometrics-assisted ATR-IR spectroscopy for direct quantitation of caffeic acid and rosmarinic acid in Thunbergia laurifolia leaves
}

\author{
Chaweewan Suwanvecho ${ }^{1}$, \\ Phatharaphisit \\ Suphakijudomkarn ${ }^{1}$, \\ Sukkamol Chinoraso ${ }^{1}$, \\ Pongtip Sithisarn ${ }^{2}$, \\ Piyanuch Rojsanga ${ }^{1 *}$ \\ 1 Department of Pharmaceutical \\ Chemistry, Faculty of Pharmacy, Mahidol \\ University, Bangkok, 10400, Thailand \\ 2 Department of Pharmacognosy, Faculty \\ of Pharmacy, Mahidol University, \\ Bangkok,10400, Thailand
}

*Corresponding author:

Piyanuch Rojsanga

Piyanuch.roj@mahidol.ac.th

\section{KEYWORDS:}

Thunbergia laurifolia; Caffeic acid; Rosmarinic acid;

Attenuated total reflectance infrared spectroscopy; High performance liquid chromatography

\begin{abstract}
Partial least squares-1 (PLS-1), a chemometrics-assisted attenuated total reflectance infrared (ATR-IR) spectroscopy method, for quantitative analysis of caffeic acid and rosmarinic acid contents in Rang Chuet (Thunbergia laurifolia Lindl.) leaf samples was developed and validated. PLS-1 models were performed by using 69 IR spectra of calibration set samples. Leave-one-out cross validation was utilized for model construction. Prediction efficiency of the optimum model was checked from the 24 determination results of test set samples which were not contributed in modelling step. The optimum PLS-1models for quan titative analysis of caffeic acid and rosmarinic acid contents were constructed from the first derivative pretreated IR spectral data in the wave number range $700-1,700,2,800-3,020 \mathrm{~cm}^{-1}$ and $700-1,700 \mathrm{~cm}^{-1}$, respectively. The final PLS-1 models were validated for linearity and range, accuracy, specificity and precision according to ICH guideline. The validation results were found acceptable in every validation parameters. Highperformance liquid chromatography (HPLC) method was used as a standard method for comparison of caffeic acid and rosmarinic acid contents throughout the study. From the results, caffeic and rosmarinic contents in $T$. laurifolia leaf samples collected from different locations in Thailand ranged from $0.62-1.90$ and 1.12-4.56 $\mathrm{mg} / \mathrm{g}$ of dried weight, respectively. The results of the tested set of $T$. laurifolia leaf samples obtained from the developed PLS-1 models were not significantly different with those obtained from HPLC method.
\end{abstract}

\section{INTRODUCTION}

Thunbergia laurifolia Lindl (Acanthaceae) or Rang Chuet is a widely used herbal drug which is assigned in Thailand National Drug List of Essential Medicine. Capsule and infusion preparations of the leaves have been indicated for treatments of fever and aphthous ulcer ${ }^{1}$. Traditionally, the dried leaves have been used as antipyretic agent and detoxifying agent for poisoning including insecticide, ethyl alcohol, arsenic, and strychnine poisoning ${ }^{2,3}$. Phytochemicals isolated from the aerial part of $T$. laurifolia were apigenin and its glycosides, caffeic acid, rosmarinic acid, gallic acid, and protocatechuic acid ${ }^{4,5}$. The reported biological activities of $T$. laurifolia are including antioxidant, antiinflamatory, hepatoprotective, 


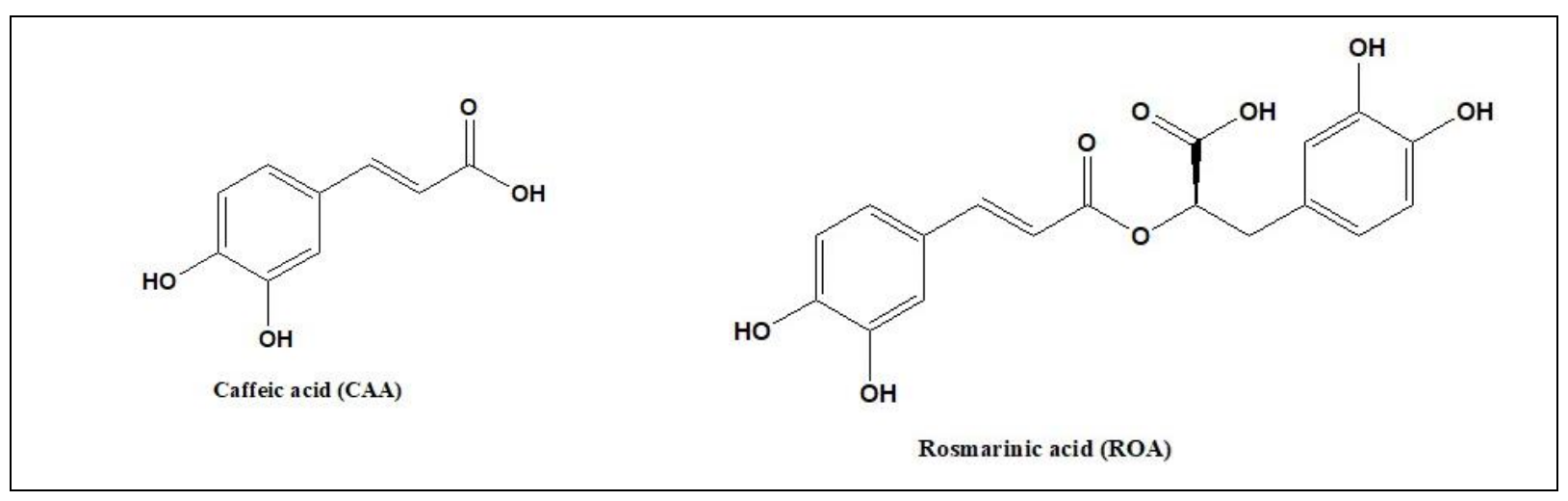

Figure 1. Chemical structures of caffeic acid (CAA) and rosmarinic acid (ROA)

antimutagenic and antifungal activities ${ }^{6-10}$ and also ameliorated cognitive and emotional deficits in animal mode ${ }^{11}$. In our previous study, caffeic acid (CAA) and rosmarinic acid (ROA) (Figure 1) were identified as major constituents in the aqueous extract of $T$. laurifolia leaves ${ }^{12}$. HPLC method was also optimized using Design of Experiment (DOE) process and validated for quantitative analysis of caffeic acid and rosmarinic acid contents in $T$. laurifolia leaves collected from different locations of Thailand ${ }^{12}$.

Now a day, chromatographic method such as high-performance liquid chromatography (HPLC), a standard which is usually performed to quantitative determine phenolic compounds in a plant extract. Although HPLC could provide an accurate and precise result, sample extraction with a suitable solvent and tedious laboratory steps are required. On the other hand, attenuated total reflectance infrared spectroscopy (ATR-IR) is a simple, rapid technique and can provide nondestructive analysis. There was report that infrared spectroscopy could be used to determine ROA content in Lamiaceae family plant ${ }^{13}$. $T$. laurifolia leaves are one of the major plant commercially available in herbal markets in Thailand, however, there is no report about the method to directly quantitative analyze of the active constituents compare to the standard analytical method. Therefore, this study was aimed for the introduction of ATR-IR method combined with chemometrics as an alternative method for quantitative determination of CAA and ROA in $T$. laurifolia or Rang Chuet leaf samples. A PLS-1 approach was developed and validated for intended purpose.

\section{MATERIALS AND METHODS}

\subsection{Plant samples}

Fourteen samples of Rang Chuet (Thunbergia laurifolia Lindl.) leaves from 12 different locations around Thailand were collected between February-October, 2015 (Table 1). Plant samples were identified by comparison with the authentic specimen at Bangkok Herbarium ( VF 064382). The Voucher specimen (VK 064382) was kept at Department of Pharmaceutical Chemistry, Faculty of Pharmacy, Mahidol University, Bangkok, Thailand. The fresh leaf samples were dried in the hot air oven at $60^{\circ} \mathrm{C}$ for

Table 1. Sources of Thunbergia laurifolia leaf samples

\begin{tabular}{cc}
\hline Location & Number of sample \\
\hline Khon Kaen & 1 \\
Chiang Rai & 1 \\
Nakhon Si Thammarat & 1 \\
Nonthaburi & 1 \\
Prachin Buri & 1 \\
Pattani & 1 \\
Phrae & 1 \\
Srisaket & 1 \\
Suphan Buri & 1 \\
Sa Kaeo & 3 \\
Bangkok & 1 \\
Nakhon Pathom & 1 \\
\hline
\end{tabular}


8 hours and then they were ground into the powder using electric mill. The powder samples were passed through the sieve No.35 to obtain the powder with particle size smaller than $0.5 \mathrm{~mm}$.

\subsection{Measurement of IR spectra of standard CAA, ROA and plant powdered samples}

IR spectra of standards CAA and ROA (Sigma-Aldrich, Germany) and plant powdered samples were measured by Nicolet iS5 Fourier transform infrared spectrophotometry (Thermo scientific, USA). The spectra were measured directly using attenuate total reflectance (ATR) mode and software OMNIC spectra. The standards were prepared in the mixing powder ratio 1: 100 between standard and $\mathrm{KBr}$. The powder of standard mixing powder and plant powdered samples were measured directly without additional sample preparation by using built- in ATR accessory. The resolution of measurement was $4 \mathrm{~cm}^{-1}$.

\subsection{Development of PLS-1 models from IR Spectra}

All fourteen samples were divided into 93 sub-samples. IR spectra of 93 sub-samples were collected and divided into 2 groups, 69 subsamples were used as calibration set samples and the left 24 sub-samples were used as the test set samples. IR spectral data of calibration set samples were subjected to the Unscrambler program to construct PLS-1 models for determination of CAA and ROA contents. The real values of CAA and ROA contents in each calibration and test set sample were obtained by HPLC analysis from our previous published method ${ }^{12}$. The models were built up from the original IR spectral data as well as the pretreated data. The several wavelength intervals were tried for an optimum PLS-1 model. The optimum of PLS- 1 models were evaluated and selected from model parameters i. e. , coefficient of determination $\left(\mathrm{R}^{2}\right)$ and root mean square error of calibration ( RMSEC). The efficiency of the models was confirmed by comparison of the results obtained from test set samples which were not used in the modeling step.

\subsection{Validation of PLS-1 models}

Method validation of the developed PLS1 models for determination of CAA and ROA was obtained to prove method validity. The parameters for a quantitation method i. e., linearity and range, accuracy and specificity, and precision were evaluated ${ }^{14}$.

\subsubsection{Linearity and range}

Linearity of IR methods was confirmed by plotting the determination values which were the method responds ( $\mathrm{Y}$-axis) and the true concentrations from HPLC method ( $\mathrm{X}$-axis). The correlation coefficient (r) greater than 0.995 was acceptable ${ }^{15}$. Range, the upper and lower application levels of the method, was inferred from linearity, accuracy and precision results.

\subsubsection{Accuracy and specificity}

Since IR is a spectroscopic method that lacks of specificity according to ICH definition, accuracy and specificity of this candidate IR method would be confirmed by comparing with the second well characterized or standard procedure. In this study, the results of the same samples obtained from HPLC method were compared to prove the accuracy and specificity of the IR method. Specificity of IR method was evaluated using $t$ - test analysis ( Microsoft ${ }^{\circledR}$ Excel) to compare the results of CAA and ROA contents obtained from IR and HPLC methods. Non-significant difference of $t$-test indicated to specificity of IR method. The accuracy of IR method was evaluated from the plot of the determination results from IR method versus those obtained from HPLC method. The slope of the plot around 1.0 indicated to agreement of the results from the two methods ${ }^{14}$.

\subsubsection{Precision}

Precision of IR method was evaluated for repeatability and intermediate precision. For repeatability, six homogenous Rang Chuet leaf samples from Bangkok were determined by the developed IR method. The relative standard deviation of the six determinations was used to declare repeatability of the method. For intermediate precision, the results obtained from two analysts were combined and calculated for the relative standard deviation. The acceptance criteria of precision was used HorRat between $0.5-2^{16}$. The relative standard deviation $(\operatorname{RSD}(\mathrm{r}))$ and HorRat were calculated by the following equations. 


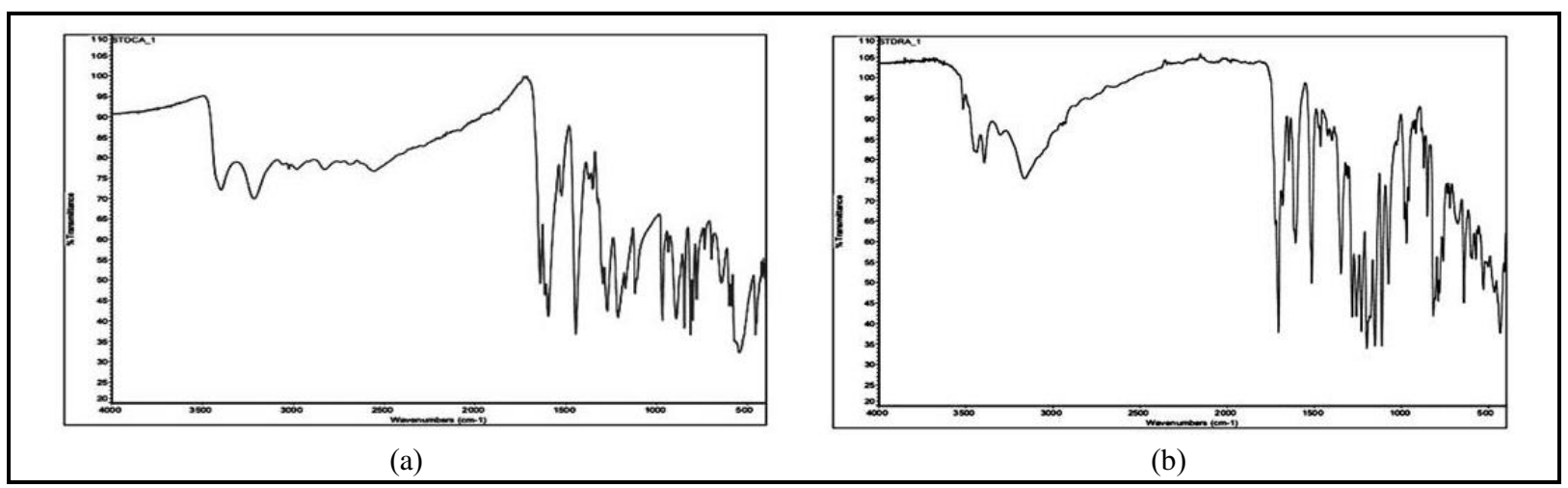

Figure 2. IR Spectra of standard CAA (a) and ROA (b)

$$
\begin{aligned}
\text { HorRat } & =\frac{R S D(r)}{p R S D(R)} \\
R S D(r) & =\frac{(S D \times 100)}{\bar{x}} \\
\operatorname{pRSD}(\mathrm{R}) & =\mathrm{C}^{-0.1505}, \text { where } \mathrm{C} \text { is the }
\end{aligned}
$$

mass fraction and analyte in sample

\subsection{Quantitative analysis of CAA and ROA by HPLC method ${ }^{12}$}

Since, the contents of CAA and ROA from HPLC method were required to compare with the results obtained from PLS- 1 method, our previous published HPLC method was utilized for quantitative analysis of CAA and ROS contents in every Rang Chuet leaf samples. Briefly, the HPLC procedure was performed using Shimadzu LC-10 system (Shimadzu, Kyoto, Japan) equipped with a model series LC-10 ADVP pump, SCL-10 AVP system controller, DGU-12 A degasser and a SPDM10A diode array detector with C18 column (Hypersil BDS, $150 \mathrm{~mm} \times 4.6 \mathrm{~mm}$ i.d., $5 \mu \mathrm{m}$ ) (Thermo Scientific, Massachusetts, USA). The mobile phase solvents were $8.5 \%$ phosphoric acid, $\mathrm{pH} 2.5$ ( solvent A) and acetonitrile (solvent B). The gradient elution was performed to elute sample components. Diode array detector was set at $330 \mathrm{~nm}$ and mobile phase flow rate was 1.0 $\mathrm{mL} / \mathrm{min}$. Sample and standard preparations were conducted as previously described ${ }^{12}$.

\section{RESULTS AND DISCUSSION}

\subsection{Determination of IR spectra of standard CAA and ROA}

Infrared spectra of CAA and ROA showed specific fingerprints with several peaks which are corresponding to the functional groups in their structures (Figure 2 and Table 2). However, there was a report indicated that the contents of CAA and ROA in the leaves of Rang Chuet are quite low, usually lower than $6 \mathrm{mg} / \mathrm{g}^{12}$. Therefore, the characteristics IR peak of CAA and ROS in the leaves of Rang Chuet could be interfered by the peaks from the functional groups of other phytochemicals and the matrices of Rang Chuet leaves. From this limitation, direct quantitative analysis of CAA and ROS content in Rang Chuet leaves from their IR spectra is hard to conduct. Partial-least square regression (PLS1), a powerful chemometrics tool, was utilized to overcome this quantitation problem. By applying PLS- 1 with IR spectra, the contents of CAA and ROA in Rang Chuet leaves could be determined without prior sample preparation.

Table 2. IR spectra of CAA and ROA

\begin{tabular}{lll}
\hline \multirow{2}{*}{ Functional group } & \multicolumn{2}{c}{ IR spectra $\left(\mathrm{cm}^{-1}\right)$} \\
\cline { 2 - 3 } & \multicolumn{1}{c}{ CAA } & \multicolumn{1}{c}{ ROA } \\
\hline O-H stretching & 3214,3398 & $3166,3393,3451,3516$ \\
C-H stretching & 2557 & 1646,1705 \\
C=O stretching & 1640 & $1513,1607,1617$ \\
C=C stretching & 1596,1615 & 1347,1463 \\
O-H bending & 1351,1445 & $1112,1151,1198,1229,1258,1282$ \\
C-O stretching & $1118,1173,1213,1272$ & $883,916,927,958$ \\
C=C bending & $892,935,967$ & $721,734,759,781,790,817,850$ \\
C-H bending & $736,779,800,814,848$ & \\
\hline
\end{tabular}


Table 3. Models parameters of PLS-1 models for determination of CAA and ROA

\begin{tabular}{lcc}
\hline \multicolumn{1}{c}{ Model parameters } & \multicolumn{2}{c}{ Substances } \\
\cline { 2 - 3 } & CAA & ROA \\
Wavelength $\left(\mathrm{cm}^{-1}\right)$ & $700-1,700$ & $700-1,700,2,800-3,020$ \\
Number of latent factors & 6 & 9 \\
$\mathrm{R}^{2}$ & 0.9636 & 0.9822 \\
RMSEC $(\mathrm{mg} / \mathrm{g})$ & 0.0803 & 0.1792 \\
\hline
\end{tabular}

* RMCSE $=$ Root mean square error of calibration

\subsection{Development of PLS-1 models for determination of CAA and ROA}

The parameters of the optimum PLS- 1 models for determination of CAA and ROA in Rang Chuet leaves were illustrated in Table 3. The PLS1 models were attempted to construct from original IR spectral data and various preprocessing IR spectral data including first and second derivatives, standard normal variate (SNV) and multiplicative scatter correction (MSC). The results were clearly seen that the models from the first derivative using Savitzky-Golay's method were better than models from other preprocessing methods (data not show) and the original spectral data. The full wavelength spectra and certain wavelength regions were also tried to perform the best PLS- 1 models. The determination results of test set samples of the final models were displayed in Table 4. The optimum
PLS-1models for quantitative analysis of caffeic acid and rosmarinic acid contents were constructed from the first derivative pretreated IR spectral data in the wave number range $700-1,700,2,800-3,020 \mathrm{~cm}^{-1}$ and $700-1,700 \mathrm{~cm}^{-1}$, respectively.

\subsection{Validation of PLS-1 model}

The developed PLS-1 models with IR spectra for quantitative determination of CAA and ROA were validated for linearity, accuracy and specificity, precision (repeatability and intermediate precision).

\subsubsection{Linearity}

As shown in Figure 3, linearity graphs of CAA and ROA were linear with the good correlation coefficient (r) greater than 0.99 .

Table 4. The determination results of test set samples

\begin{tabular}{ccccccc}
\hline \multirow{2}{*}{ Samples } & \multicolumn{3}{c}{ CAA $(\mathrm{mg} / \mathrm{g})$} & \multicolumn{3}{c}{ ROA $(\mathrm{mg} / \mathrm{g})$} \\
\cline { 2 - 7 } T1 & IR & HPLC & \% Recovery & IR & HPLC & \% Recovery \\
T2 & 0.80 & 0.79 & 101.24 & 3.76 & 3.75 & 100.35 \\
T3 & 0.62 & 0.59 & 104.52 & 1.57 & 1.54 & 102.41 \\
T4 & 1.72 & 1.78 & 96.51 & 1.12 & 1.01 & 111.44 \\
T5 & 1.11 & 1.04 & 106.63 & 2.46 & 2.46 & 100.15 \\
T6 & 0.85 & 0.89 & 95.09 & 4.09 & 4.21 & 97.31 \\
T7 & 1.36 & 1.42 & 95.63 & 3.86 & 3.57 & 108.05 \\
T8 & 1.37 & 1.42 & 95.84 & 3.53 & 3.57 & 98.90 \\
T9 & 1.35 & 1.42 & 95.00 & 3.63 & 3.57 & 101.48 \\
T10 & 1.38 & 1.42 & 97.11 & 3.36 & 3.57 & 94.15 \\
T11 & 1.83 & 1.79 & 102.42 & 4.30 & 4.00 & 107.64 \\
T12 & 1.72 & 1.79 & 95.99 & 4.19 & 4.00 & 104.71 \\
T13 & 1.77 & 1.79 & 98.73 & 4.01 & 4.00 & 100.39 \\
T14 & 1.79 & 1.79 & 99.79 & 4.00 & 4.00 & 100.09 \\
T15 & 1.84 & 1.79 & 102.81 & 4.41 & 4.00 & 110.24 \\
T16 & 1.81 & 1.79 & 101.08 & 4.56 & 4.00 & 114.04 \\
T17 & 1.78 & 1.79 & 99.57 & 4.38 & 4.00 & 109.47 \\
T18 & 1.90 & 1.79 & 106.22 & 4.07 & 4.00 & 101.74 \\
T19 & 1.67 & 1.79 & 93.31 & 3.65 & 4.00 & 91.28 \\
T20 & 1.79 & 1.79 & 100.07 & 4.05 & 4.00 & 101.26 \\
T21 & 1.75 & 1.79 & 97.56 & 4.02 & 4.00 & 100.64 \\
T22 & 1.69 & 1.79 & 94.54 & 3.87 & 4.00 & 96.74 \\
T23 & 1.88 & 1.79 & 105.05 & 4.07 & 4.00 & 101.76 \\
T24 & 1.68 & 1.79 & 93.98 & 3.61 & 4.00 & 90.33 \\
Mean & 1.87 & 1.79 & 104.26 & 4.16 & 4.00 & 104.04 \\
SD & 1.56 & 1.57 & 99.29 & 3.70 & 3.63 & 102.03 \\
\% RSD & 0.37 & 0.37 & 4.13 & 0.84 & 0.81 & 5.99 \\
\hline & 23.92 & 23.66 & 4.16 & 22.74 & 22.24 & 5.87 \\
\hline
\end{tabular}



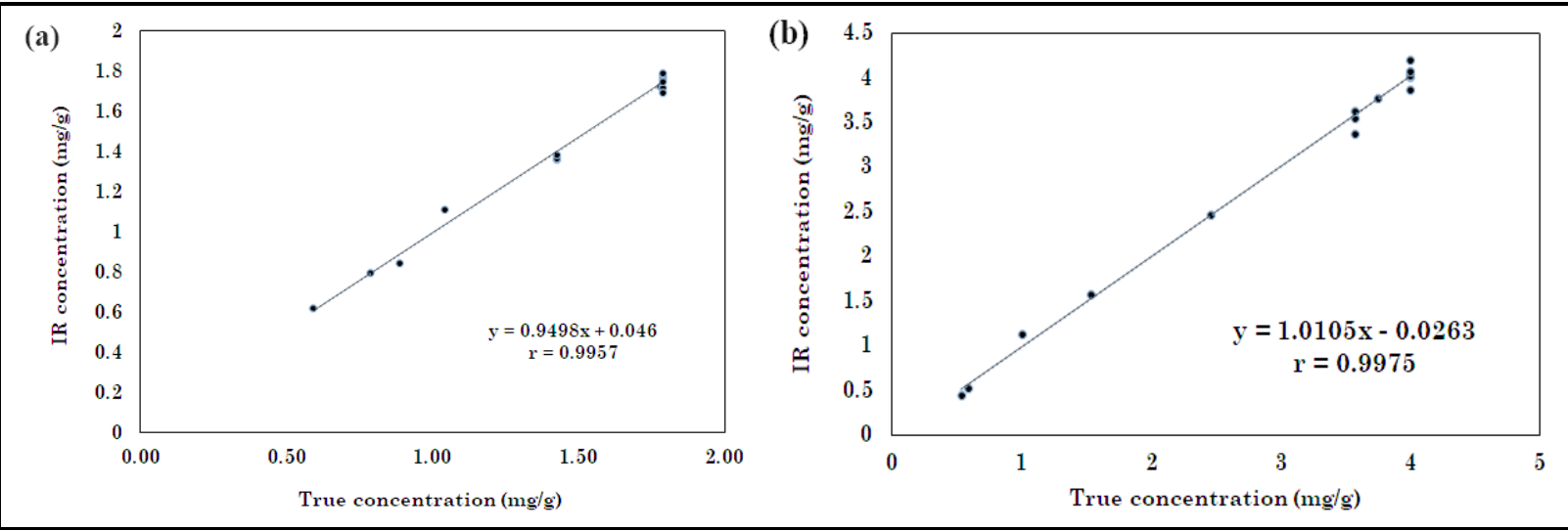

Figure 3. Linearity graphs of CAA (a) and ROA (b)

\subsubsection{Accuracy and specificity}

As shown in Table 5, the range of $\pm 95 \%$ confident limit of the slope of the plots were covered 1.0 for both CAA and ROA. In addition, the determination results obtained from IR and HPLC methods were not significant different ( $P$ $>0.05$ ). These results implied to the accuracy and specificity of IR method.

\subsubsection{Precision}

Since the contents of CAA and ROA in the current samples were about 2 and $5 \mathrm{mg} / \mathrm{g}$, the mass fraction values (C) equal 0.002 and 0.005 were used to calculate $\operatorname{pRSD}(\mathrm{R})$ in HorRat equation. Therefore, $\operatorname{RSD}(\mathrm{r})$ range of $1.27 \%$ $5.10 \%$ for CAA and $1.11 \%-4.44 \%$ for ROA was acceptable for the HorRat criteria between 0.52.0. As the results showed in Table 6, HorRat values of CAA and ROA determinations were within acceptance criteria for repeatability and intermediate precision. These results confirmed that IR method was efficiently precise for the application in real samples.

\subsection{Quantitative analysis of CAA and ROA by HPLC method}

The determination results of CAA and ROA contents obtained from the developed PLS1 using IR method were compared to the results from our previous HPLC method. As shown in Table 4, the contents of CAA and ROA in 24 Rang Chuet leaf samples ranged from 0.62-1.90 and $1.12-4.56 \mathrm{mg} / \mathrm{g}$ of dried weight, respectively. Moreover, the determination results obtained from IR and standard HPLC methods were not significantly different according to $P$-values from t-test higher than 0.5 (Table 4).

Table 5. Accuracy and specificity of IR method

\begin{tabular}{lcc}
\hline \multirow{2}{*}{ Parameters } & \multicolumn{2}{c}{ Substances } \\
\cline { 2 - 3 } & $\mathrm{CAA}$ & $\mathrm{ROA}$ \\
\hline Plot equation & $\mathrm{Y}=0.9498 \mathrm{X}+0.046$ & $\mathrm{Y}=1.0141 \mathrm{X}-0.031$ \\
$\pm 95 \%$ of the slope & $0.8970-1.0027$ & $0.9744-1.0538$ \\
t-test $(P$-value $)$ & 0.903 & 0.791 \\
\hline
\end{tabular}

Table 6. Precision of CAA and ROA

\begin{tabular}{cccccc}
\hline & CAA $(\mathbf{m g} / \mathbf{g})$ & \multicolumn{3}{c}{ ROA $(\mathbf{m g} / \mathbf{g})$} \\
\hline Sample & Analyst 1 & Analyst 2 & Sample & Analyst 1 & Analyst 2 \\
\hline 1 & 1.83 & 1.67 & 1 & 4.30 & 4.07 \\
2 & 1.72 & 1.79 & 2 & 4.19 & 4.05 \\
3 & 1.77 & 1.75 & 3 & 4.01 & 4.02 \\
4 & 1.79 & 1.69 & 4 & 4.00 & 3.87 \\
5 & 1.84 & 1.88 & 5 & 4.41 & 4.07 \\
6 & 1.81 & 1.68 & 6 & 4.38 & 4.16 \\
\hline Average & 1.79 & 1.76 & Average & 4.22 & 4.04 \\
\% RSD (n=6) & 2.34 & 4.95 & \% RSD (n =6) & 4.22 & 2.37 \\
\% RSD (n=12) & & 3.80 & \multicolumn{3}{c}{3.98} \\
\hline
\end{tabular}




\section{CONCLUSION}

It could be summarized that PLS- 1, a chemometric-assisted IR spectroscopic method was successfully developed for intended purpose. The developed IR method came with some advantages e.g., simple measurement without sample preparation and high-sample through put. As the results shown in this work, IR method combined with PLS-1 could be applied very well for quantitative analysis of CAA and ROA contents in Rang Chuet leaf samples. In addition, the obtained analytical results were not significant different from the results from HPLC method which was the standard determination procedure.

\section{ACKNOWLEDGEMENTS}

This work was financially supported by Agricultural Research Development Agency (Public Organization).

\section{Conflict of interest}

There is no potential conflict of interest.

\section{Funding}

This work was financially supported by Agricultural Research Development Agency (Public Organization), grant number CRP 6105020190.

\section{Ethical approval}

None to declare

\section{Article info:}

Received May 14, 2019

Received in revised form October 19, 2019

Accepted November 21, 2019

\section{REFERENCES}

1. National Drug Committee. List of Herbal Medicinal Products A.D. 2013; Food and Drug Administration; Ministry of Public Health, 2013.

2. Thongsaard W; Marsden CA. A herbal medicine used in the treatment of addiction mimics the action of amphetamine on in vitro rat striatal dopamine release. Neurosci Lett. 2002; 329: 129-32.

3. Thongsaard W, Marsden CA, Morris P, Prior M, Shah YB. Effect of Thunbergia laurifolia, a Thai natural product used to treat drug addiction, on cerebral activity detected by functional magnetic resonance imaging in the rat. Psychopharmacology (Berl.). 2005; 180: 752-60.
4. Oonsivilai R, Cheng C, Bomser J, Ferruzzi MG, Ningsanond S. Phytochemical profiling and phase II enzyme- inducing properties of Thunbergia laurifolia Lindl. (RC) extracts. J. Ethnopharmacol. 2007;114:3006.

5. Suwanchaikasem P, Chaichantipyuth C, Sukrong S. Antioxidant-guided isolation of rosmarinic acid, a major constituent from Thunbergia laurifolia, and its use as a bioactive marker for standardization. Chiang Mai J Sci. 2014; 41: 117-27.

6. Boonyarikpunchai $\mathrm{W}$, Sukrong $\mathrm{S}$, Towiwat P. Antinociceptive and anti- inflammatory effects of rosmarinic acid isolated from Thunbergia laurifolia Lindl. Pharmacol Biochem Behav. 2014; 124: 67-73.

7. Moongkarndi $\mathrm{P}$, Kosem $\mathrm{N}$, Luanratana $\mathrm{O}$, Jongsomboonkusol S, Pongpan N. Antiproliferative activity of Thai medicinal plant extracts on human breast adenocarcinoma cell line. Fitoterapia. 2004;75:375-7.

8. Pramyothin $\mathrm{P}$, Chirdchupunsare H, Rungsipipat A, Chaichantipyuth C. Hepatoprotective activity of Thunbergia laurifolia Linn extract in rats treated with ethanol: in vitro and in vivo studies. J Ethnopharmacol. 2005; 102: 408-11.

9. Ussanawarong S, Mahakunakorn $\mathrm{P}$, Tessiri T, Porasupattana S. Effect of Thunbergia Laurifolia Linn. on detoxication of paraquat. KKU Res J. 2005, 5, 11

10. Wonkchalee $\mathrm{O}$, Boonmars $\mathrm{T}$, Aromdee $\mathrm{C}$, Laummaunwai P, Khunkitti W, Vaeteewoottacharn K, et al. Anti-inflammatory, antioxidant and hepatoprotective effects of Thunbergia laurifolia Linn. on experimental opisthorchiasis. Parasitol Res. 2012; 111: 353-9.

11. Rojsanga P, Sithisarn P, Tanaka K, Mizuki D, Matsumoto K. Thunbergia laurifolia extract ameliorates cognitive and emotional deficits in olfactorectomized mice. Pharmaceutical biology. 2005; 53: 1141-8.

12. Ruangpayungsak N, Sithisarn P, Rojsanga P. High performance liquid chromatography fingerprinting and chemometric analysis of antioxidant quality of Thunbergia laurifolia leaves. J Liq Chromatogr Relat Technol. 2018; 41(11):713-21.

13. Saltas D, Pappas CS, Daferera D, Tarantilis PA, Polissiou MG. Direct determination of rosmarinic acid in Lamiaceae herbs using diffuse reflectance infrared Fourier transform spectroscopy (DRIFTS) and chemometrics. J Agric Food Chem, 2013; 61(13): 3235-41.

14. The United States Pharmacopeial Convention, The United States Pharmacopeia 41 The National Formulary 36, Rockvill 2018.

15. United States Food and Drug Administration. Methods, method verification and validation laboratory procedure (ORA-LAB.5.4.5) [document on the Internet]. Office of Regulation Affair (ORA); 2014 [updated 2014 August 29; cited 2019 April 30]. Available from: http://www.fda.gov/ ora/science_ref/lm/default.htm.

16. Association of Official Analytical Collaboration (AOAC) International. AOAC guidelines for single laboratory validation of chemical methods for dietary supplements and botanicals [document on the Internet]. 2002 [updated 2002 December 19; cited 2019 April 30]. Available from: http://www.aoac.org/imis15_prod/AOAC_ Docs/StandardsDevelopment/SLVGuidelines_Dietary_ Supplements.pdf. 